\title{
Comparing Special Education Teachers' Personality Profile With Their Choice to Teach
}

Excelsior: Leadership in Teaching and Learning 2021, Vol. 14(1), 20-35 (C) The Author 2021 CC-BY 4.0 International Reprints and permissions: surface.syr.edu/excelsior https://doi.org/10.14305/i n.19440413.2021.14.1.02

nyacte.org

\section{(i) LaRon A. Scott ${ }^{1}$, (i) Lauren Bruno ${ }^{2}$, (i) Philip Gnilka ${ }^{1}$, Lindsay Kozachuk $^{3}$, (i) Katherine Brendli ${ }^{4}$, and Vivian Vitullo ${ }^{1}$}

\begin{abstract}
Researchers have yet to examine the association of Holland personality profiles as it relates to special education teachers. In response to this need, we report the personality and vocational profiles (Holland Codes) of 134 special education teachers across a special education training program. The purpose of this paper is to summarize findings from the Self-Directed Search measure commonly used to assess the personality of participants in an occupation and suggest implications for participants' choice in becoming a special education teacher. Our focus was on personality match with vocational choice to include participants' demographic (e.g., gender, race/ethnicity, and geographical location) profile.

Findings from the study reveal that while special educators' overall personality profile is congruent with the Holland Codes associated with special education teachers, other features may explain participants' choice to pursue a career as a special education teacher. Implications for teacher preparation programs and $\mathrm{K}-12$ schools training are recommended based on the research findings.
\end{abstract}

\section{Keywords}

teacher retention, teacher attrition, personality profile, teacher education

\footnotetext{
${ }^{1}$ Virginia Commonwealth University

${ }^{2}$ Washington State University

${ }^{3}$ Pam Beach Atlantic University

${ }^{4}$ Cornell University

Corresponding Author:

LaRon A. Scott, Virginia Commonwealth University School of Education, Box 842020, 1015 West Main Street, Richmond, VA 23284-2020

Email: scottla2@vcu.edu
} 
Attrition rates for special education teachers (SETs) in the United States (U.S.) contribute to a severe and persistent shortage of licensed teachers needed to deliver special education services to students with disabilities (SWDs)-negatively impacting Kindergarten- $12^{\text {th }}$ grade schools and outcomes for SWDs (Hagaman \& Casey, 2017). The number of students with disabilities in U.S. K-12 schools has increased from 6.5 million in 2009-2010 to 7.3 million in the 2019-2020 school year (Individuals with Disabilities Education Act, 2004), requiring an increase in the number of SETs to meet the needs of these students. However, 48 states, plus the District of Columbia, report critical shortages in special education (U.S. Department of Education, 2018).

Contributing to shortage areas are the turnover rates of SETs (Carver-Thomas \& DarlingHammond, 2017). Turnover rates are either due to educators moving to another school or leaving the field altogether (Goldring et al., 2014), with 6.6\% of SETs leaving the field entirely (NCES, 2018). In addition, SETs are 2.5 times more likely to leave the profession as teachers in general education (Smith \& Ingersoll, 2004; Sutcher et al. 2016). Largely, SET attrition negatively impacts the learning opportunities for SWDs and threatens their quality of access to individualized education and interventions.

\section{Special Education Teacher Attrition}

With special education being a critical shortage area in most of the U.S., there is a need to decrease the high rates of teacher attrition: teachers who leave, move, or transfer schools (Billingsley \& Bettini, 2019). Therefore, researchers have sought to investigate the reasons for the high attrition rates. Findings pointed to teacher preparation, school culture and climate, working conditions, and teacher demographics as main categories contributing to SET attrition (Billingsley \& Bettini, 2019). Specific workplace factors that lead to high attrition rates include lack of administrative support, poor teacher team efficacy, and lack of mentoring or support in the early years of teaching (Conley \& You, 2017; Ingersoll et al., 2017b). Other factors that lead to high burnout and stress levels may include the amount of paperwork, large caseloads, emotional exhaustion, and lack of support and collaboration (Bettini et al., 2017; Billingsley \& Bettini, 2019; Mehrenberg, 2013). Additional factors may also include teacher demographics (i.e., race, age, years of experience), poor working conditions, retirement, financial reasons, and student disengagement as reasons teachers leave the field or move to general education classrooms (Billingsley \& Bettini, 2019; Conley \& You, 2017; Scott et al., 2021). This line of research indicates complex reasons SETs may leave and highlights the need to better narrow what factors best predict SETs retention.

\section{Special Education Teacher Recruitment and Retention}

While the reasons for attrition have been investigated, there have also been initiatives and recommendations on better ways to recruit and retain teachers that include increasing salaries, enhancing the preparation of teachers, increasing support through mentoring, and improving teaching conditions (Billingsley \& Bettini, 2019; Sutcher et al., 2016). Therefore, if salaries become more competitive, teachers are more likely to stay, which indicates that teachers are more likely to leave the field in districts with lower wages (Beteille et al., 2009; Grissom et al., 2015). Further, teachers who feel more prepared and have pedagogical knowledge are more likely to stay in the field longer than those who have not (e.g., Connelly \& Graham, 2009; Ingersoll et al., 2014). Lastly, teachers who reported 
feeling supported and receiving administrative and/or mentoring support have been known to stay longer than those who have not (Ingersoll \& Strong, 2011). While these suggestions have been disseminated, there is still a need to better understand why SETs choose to stay or leave the field.

\section{Personality and Attrition}

Research indicates burnout and stress are key factors for high rates of SET attrition; yet also supports a connection between personality, burnout, stress, and work environments (Jennings, 2008; Zysberg et al., 2017). Therefore, an investigation into SETs personality profile may help to better understand the reasons SETs are staying or leaving. For example, Zysberg et al., (2017) in a study examining the personality of 230 daycare employees, noted personality, levels of stress, and emotional intelligence were positively correlated with high rates of burnout, a cause for high rates of attrition. A meta-analysis review by Kim et al. (2019) of personality associated teachers' personality with feelings of effectiveness and burnout. For example, teacher emotional stability, extraversion, and consciousness were negatively correlated with burnout. This indicated that if teachers had low levels of extraversion, they were more likely to burnout.

Further, when teachers have feelings of low self-efficacy, they are also more likely to leave the field of teaching (Skaalvik \& Skaalvik, 2010). As personality influences burnout and effectiveness, other areas related to personality are career choice and likeliness to remain in a position (Maslach \& Schaufeli, 2001). For instance, when individuals had the personality that matched that of a teacher, they rated the highest in teaching self-efficacy, work engagement, and job satisfaction (Perera et al., 2018), all qualities associated with retention. This is supported by the work of Robinson et al., (2019), who indicated that SETs who were more satisfied with their jobs were less likely to experience burnout and more likely to remain in their positions.

Personality fit. As mentioned, an individual's personality fit may be linked to career choice and longevity in employment (Kristof, 1996). Personality fit identifies the compatibility between a person and their profession and can influence an individual's decision to stay or go. For example, researchers investigating the personality profiles of language teachers revealed a link between the educators' vocational identity (personality profile/career match) and their likelihood to remain in or leave the profession (Swanson, 2012). Swanson (2012) referenced the Holland Codes proposal, stating that "people search for environments that will let them exercise their skills and abilities, express their attitudes and values, and take on agreeable problems and roles" (Swanson, 2012, p. 22). This indicates that individuals are more likely to continue employment in an organization or job that is matched to their personalities. The concept of personality profiles as predictors of perseverance in a profession seems promising if applied to the SET workforce. Personality profiles could allow for a better understanding of the characteristics of SETs entering and leaving the field, potentially identifying predictors of a personality fit that is conducive to sustained employment in the field (Swanson (2012). Yet, to our knowledge, no research was conducted at the time of this study which investigated the personalitycareer profiles of SETs, and their relevance to a SET likelihood to remain in or leave the profession.

While the field of special education experiences high attrition rates with teachers (Carver-Thomas \& Darling-Hammond, 2017), including teachers from diverse demographic backgrounds (e.g., race/ethnicity, gender; Ingersoll et al., 2017a), predictors of perseverance in the field have yet to be identified, despite the potential to use this information as a tool to increase retention rates for SETs. 
Given the correlation between vocational profile and personality fit (Holland, 1997; Swanson, 2012), we posit that personality profiles may serve as a tool for teacher preparation programs and $\mathrm{K}-12$ schools to better understand candidates and identify preferred work environments to predict job satisfaction and long-term success of SETs.

\section{Theoretical Background: The Holland Code}

Holland (1997) proposed that personality plays a role in occupation fit and job satisfaction (Holland, 1997). According to Holland, a major contributor to the field of career counseling, individuals gravitate towards professions that match their interests, preferences, and values. His theory stems from the results of a large research study assessing the personality profiles and vocational aspirations of over 23,000 college freshmen (Holland, 1966). The participants' vocational aspirations were compared to their personality profiles, using a system Holland created to develop a series of occupation profiles (Gottfredson \& Holland, 1990). This system is known as the RIASEC, an acronym for the six personality types that he identified: Realistic, Investigative, Artistic, Social, Enterprising, and Conventional (Holland, 1966; Holland, 1997). Table 1 provides a description of the different personality types.

Table 1

Description of Personality Types

\begin{tabular}{|c|c|c|c|}
\hline Personality Type & Work Preferences & Common Professions & Common Traits \\
\hline Realistic (R) & Working with objects & Engineer, technician, cook & $\begin{array}{l}\text { Hardheaded, honest, practical, } \\
\text { shy, thrifty }\end{array}$ \\
\hline Investigative (I) & $\begin{array}{c}\text { Working } \\
\text { independently }\end{array}$ & $\begin{array}{c}\text { Doctor, biologist, airplane } \\
\text { pilot, pharmacist }\end{array}$ & $\begin{array}{l}\text { Analytical, critical, curious, } \\
\text { modest, introverted }\end{array}$ \\
\hline Artistic (A) & $\begin{array}{l}\text { Creating and } \\
\text { imagining }\end{array}$ & $\begin{array}{c}\text { Writer, editor, architect, } \\
\text { fashion designer, graphic } \\
\text { designer }\end{array}$ & $\begin{array}{l}\text { Expressive, impulsive, } \\
\text { disorderly, intuitive, open }\end{array}$ \\
\hline Social (S) & $\begin{array}{l}\text { Working with and } \\
\text { helping people }\end{array}$ & $\begin{array}{l}\text { Teacher, counselor, } \\
\text { speech therapist, nanny }\end{array}$ & $\begin{array}{l}\text { Convincing, friendly, idealistic, } \\
\text { sympathetic, understanding }\end{array}$ \\
\hline Enterprising (E) & $\begin{array}{l}\text { Persuading or } \\
\text { directing people }\end{array}$ & $\begin{array}{c}\text { Salesperson, lawyer, } \\
\text { entrepreneur, contractor, } \\
\text { newscaster }\end{array}$ & $\begin{array}{l}\text { Ambitious, agreeable, } \\
\text { extroverted, impulsive, self- } \\
\text { confident }\end{array}$ \\
\hline Conventional (C) & $\begin{array}{l}\text { Having order and } \\
\text { direction }\end{array}$ & $\begin{array}{l}\text { Accountant, data } \\
\text { manager, inspector }\end{array}$ & $\begin{array}{l}\text { Careful, practical, efficient, } \\
\text { conscientious, conforming }\end{array}$ \\
\hline
\end{tabular}

Note. This is a description of personality types (adapted from Holland, 1997) and provides a brief description of the work preferences, traits, and common professions for each of the RIASEC personality types.

Holland (1997) posited that individuals have a mix of all six personality types, with three of them being the most dominant and related to career choice. The top three personality types are combined to 
create a three-letter sequence called the Holland Code. Table 1 describes the categories of the Holland Code, which is typically made up of a combination of three letters to identify an individual's personality profile as it relates to their occupation. Holland Codes are also assigned to individual occupations. For example, of the six personality types related to career or vocational choice identified by the Holland Code, teachers typically rate the highest on the social personality type as a means of their skills for teaching and social constructs to solve problems within the workplace (Holland, 1997).

Holland suggested that individuals in a profession closely matching their own Holland Code are more likely to experience job satisfaction and fulfillment (Holland, 1997; Nauta, 2010). Conversely, individuals in professions that are starkly different from their code will find their work unsatisfying. The matching of individual personality and environment can be determined by a key feature in Holland's theory-congruence. Congruence is often described as "the degree of fit between an individual's personality type and the work environment type" (Nauta, 2010, p. 11). For instance, if a person scores highest in Social, they are likely to report more satisfaction and stability in a work environment that is predominately Social than an environment that is predominately Realistic. In fact, the fit between a person's personality and their job predicted employee intentions of leaving their job in Tak's (2011) study. Thus, congruence between an individual's personality and the work environment for SETs may be an important factor for SET retention.

As noted earlier, Swanson (2008) examined the personality profiles of 82 practicing foreign language teachers and compared them to the dictated code by Gottfredson and Holland (1990). Swanson found that the practicing foreign language teachers' personality profiles match the associated occupational code (SAE). To recognize a contrast between teachers from different disciplines, Gottfredson and Holland identified Social, Enterprising, and Conventional (SEC), as the most likely personality profile for the SET occupation. According to Holland (1997), a person with an SEC personality profile would enjoy work environments where they can interact and assist others and provide encouragement and direction in an organized, systematic way.

While recent research has not yet confirmed SEC as an occupational code for SETs, a substantial body of research supports the SEC personality traits for SETs. A person with a Social personality is often empathic, agreeable, and has strong social skills (Holland, 1997). Several research studies found that SETs have high levels of empathy and social skills (Berkovich, 2018; Platsidou \& Agaliotis, 2017; Wampold et al. 1995). Wampold et al. (1995) specifically linked such SET traits with that of the Social personality, finding that participants with the Social personality had greater social skills than participants with the other RIASEC personalities.

Researchers have yet to evaluate SETs using Holland's theory; however, many studies previously analyzed the personality of special educators using another popular personality assessment known as the Five Factor Model (FFM; Goldberg, 1990). The FFM assesses the levels of extraversion, agreeableness, conscientiousness, neuroticism, and openness in an individual. Research supports a relationship between RIASEC personality profiles and traits from FFM (Larson et al., 2002). Larson et al. (2002) found that levels of (a) extraversion and agreeableness correlate with RIASEC Social personalities; (b) extraversion and conscientiousness correlated with RIASEC Enterprising personalities; and (c) conscientiousness correlated with RIASEC Conventional personalities. Buttner et al. (2015) found that several studies endorse SEC qualities for SETs, especially personality traits of agreeableness (e.g., Merrit et al. 2012), extraversion (Prather-Jones, 2011 in Buttner et al., 2015), and conscientiousness (Goodman \& Burton, 2010 in Buttner et al., 2015), which relate to Social, Enterprising, and Conventional personalities respectively (Larson et al., 2002). However, more recent research questions the relationship between the FFM and RIASEC interests (Hurtado Rua et al., 2018), 
suggesting that it may not be as strong as previous studies reported (e.g., Larson et al., 2002). Thus, SET personality traits remain an area in need of further exploration to better understand SET personality in a career context.

Holland recommended considering the influence of demographics on personality when examining Holland Codes and job fit (Holland 1973; 1985). Several studies investigated how gender and race have influenced a person's Holland code (e.g., Fouad, 2002; Morris, 2016; Tracey \& Robbins, 2005). Researchers found that men score higher on Realistic than women, who score higher on Social (Fouad, 2002; Morris, 2016; Tracey \& Robbins, 2005). Race too influences scores with (a) Asian Americans, Indians, and Middle Easterners rating higher on Investigative and Enterprising (Fouad, 2002; Morris, 2016), (b) Pacific Islanders rating higher in Realistic, Artistic, and Social, (c) African Americans and Native Americans rating lower in Realistic, and (d) Caucasians rating lower in Conventional (Morris, 2016). Therefore, it is important for us to consider the participants' demographics when examining personality codes in the presenting study.

\section{Purpose of the Study}

Researchers have yet to examine the association of Holland personality profiles as it relates to SETs. With the pool of SETs shrinking, understanding the compatible personality profiles of SETs could help boost recruitment, increase retention, and decrease attrition in the special education field, thus providing students with better, more consistent education. Therefore, the purpose of this pilot study was to summarize detailed and descriptive data about the personality profiles of SETs entering the special education teacher workforce and identify if their profiles matched SETs occupational codes outlined by Gottfredson and Holland (1990). Specifically, the following research questions were addressed: Research Question 1: What is the personality profile of special education teachers? Research Question 2: What difference exists among special education teachers in their occupational profiles?

\section{Methods}

We examined the personality profiles of SETs while investigating the relationships between their personality profiles and demographic characteristics (e.g., gender, race/ethnicity), school setting, and number of years teaching. We conducted our study across a SET education program located at a higher education institution in the South-East region of the United States. Participants $(N=134)$ were recruited and included in this study as practicing special educators enrolled in a SET preparation program. Participants included 74\% females $(n=99) ; 60 \%$ individuals who identify as White $(n=81)$, followed by $18 \%$ individuals who are Black/African American, $8 \%$ Asian/Pacific Islander, $4 \%$ Hispanic/Latino, and 0.7\% Native American. The ages of participants ranged from 22 through 64, with the mean age being 40 years old and the median being 39 years old. Individuals reported which grade levels they taught: $56 \%$ taught secondary special education (grades 6-12), 36\% taught elementary education (K-5), and $8 \%$ of teachers reported they taught across all grade levels (i.e., both elementary and secondary). Most teachers reported teaching in a suburban school district (70\%), 15\% of teachers reported teaching in an urban setting, and the other $15 \%$ in a rural setting. Participants had a variety of years of experience, with most being in their first five years of teaching $(<1$ year $=15 \% ; 1-5$ years $=$ 
$74 \% ; 6-10$ years $=6 \% ;+10$ years $=5 \%)$. Most participants had a bachelor's degree $(n=84,63 \%)$, with almost $32 \%$ having master's degrees.

\section{Research Instrument (Data Collection)}

Self-Directed Search Form R. The Self-Directed Search (SDS; Holland \& Messer, 2013) is a selfreport measure that assesses the personality of participants in relation to occupation. The SDS consists of 252 questions in which the participant responded "yes" or "no," or "like" or "dislike" to a variety of activities, competencies, and occupations. Additionally, participants rate their skill level from one to seven (one being low and seven being high) on 12 skills that correspond with the six RIASEC personalities. Affirmative responses to activities, competencies, and occupations and scores of skill rankings are summed by RIASEC personality, providing a total of six subscale scores (one for each personality). Subscale scores range from zero to 56. In order, from highest to lowest, the three highest scores make up the participant's Summary Code or Holland Code. The SDS has sound psychometric properties (i.e., validity and reliability). Coefficients for internal consistency for the sections on activities, competencies, and occupations range from .71 to .93 , and .88 to .94 for the summary scale (Holland \& Messer, 2013).

Data collection. After receiving Institutional Review Board approval, we administered the study online through RedCap, an online electronic data collection (EDC) and management tool. The survey was sent to 248 participants, with 144 responses (58\%) and with 10 participants not fully completing the survey $(N=134)$. Reminder emails were sent to non-responders by the study team with a final thank-you email sent to all participants after two weeks.

\section{Data Analysis}

Quantitative data collected via the SDS was analyzed using an Analysis of Variance (ANOVA) to compare the means between the six personality profiles regarding the participants' demographic characteristics, helping us better understand which personality profiles were most prevalent across the various characteristics. Descriptive data, means, and standard deviations were reported when appropriate. Further, consistency and differentiation analyses were conducted to better understand the participants' scores on the SDS and the personality profile results. Finally, the data were collected and analyzed to better understand if special educator teachers possess the personality profile of Social, Enterprising, and Conventional (SEC), which is the most common personality profile for that occupation.

\section{Results}

We investigated the differences in the codes based on the independent variables. We then calculated the data and evaluated the internal consistency of the assessment by calculating the Cronbach's alpha for each subscale, which were: Realistic (.91), Investigative (.93), Artistic (.91), Social (.88), Enterprising (.93), and Conventional (.92). These results indicated the items have relatively high internal consistency, especially because a reliability coefficient of .70 or higher is considered acceptable in social science research (Creswell, 2018). 


\section{Personality Profiles of Special Educators}

We calculated the personality profiles of special educators using John Holland's SDS. We calculated means and standard deviations to determine an interest profile for the entire sample. The interest profile was Social $(M=43.90, S D=7.70)$, Conventional $(M=29.74, S D=10.07)$, and Enterprising $(M=$ 27.94, $S D=11.94)$. The Investigative domain was closely ranked fourth $(M=27.34, S D=11.85)$; whereas, Artistic $(M=24.01, S D=11.24)$ and Realistic $(M=20.51, S D=10.93)$ were ranked last. When compared to the occupation associated with the summary codes, special educators are generally a Social, Enterprising, Conventional (SEC) code; therefore, the code of Social, Conventional, and Enterprising (SCE) is accurate, as rearranging codes is possible. With the total difference in the first three scores being 15.96, it suggests there is a strong differentiated profile for the sample. On a scale from 0 to 50 , a difference of eight points or more increases the stability of the interest profile.

\section{Gender}

The Holland Code for female participants was $\operatorname{Social}(M=43.29, S D=8.10)$, Conventional $(M=$ 30.24, $S D=10.30)$, and Enterprising $(M=26.45, S D=11.76)$. Whereas the Holland Code for male participants was Social $(M=44.73, S D=6.10)$, Enterprising $(M=33.14, S D=11.76)$, and Investigative $(M=31.45, S D=13.33)$. Therefore, to evaluate the relationship between the two variables, we conducted a one-way analysis of variance (ANOVA) to evaluate the relationships between the six subscales for gender differences. Two of the six subscales showed significant differences for gender. The ANOVA for the Realistic scale $\left(F(1,100)=15.94, p<.001, \eta^{2}=.14\right)$ and the Enterprising scale $(F(1,100)=5.58, p<.05, \eta 2=.05)$ were both found to have significant differences based on gender.

\section{Setting}

A one-way ANOVA was used to evaluate the differences of location with the six subscales. Three of the six subscales showed significant differences based on location; the Artistic scale was significant $\left(F(2,102)=3.63, p<.05, \eta^{2}=.07\right)$, along with the Enterprising scale $\left(F(2,101)=4.23, p<.05, \eta^{2}=\right.$ .07 ), and Conventional scale $\left(F(2,101)=6.763, p<.05, \eta^{2}=.12\right)$. A post-hoc analysis was conducted to further examine the differences between the different groups and found that teachers in the urban group were more likely to have 10 more points in Artistic than those in the rural group (Tukey HSD, $p<$ .05). The difference between the rural-suburban, and urban-suburban and rural-urban groups were not significant in any of the other profile areas.

\section{Race/Ethnicity}

We calculated the Holland Codes for the different subgroups based on race/ethnicity. The three highest scores for each code were analyzed and varied among the different groups. All groups had social as their first highest scores; however, the other areas differ. White participants had a Social, Conventional, and Investigative (SCI) code; Hispanic/Latino participants had Social, Investigative, and Enterprising (SIE); Black/African American participants had a code of Social, Enterprising, and Conventional (SEC); and 
Asian/Pacific Islander had a Social, Conventional, Investigative (SCI) code. Therefore, to further evaluate the difference of race/ethnicity among the six subscales, we conducted a one-way ANOVA. Of the six subscales, the Enterprising subscale had a significant difference, $F(5,98)=3.31, p<.05, \eta^{2}=$ .14. There were no other significant differences based on the other five subscales.

\section{Years of Experience}

Results of a one-way ANOVA suggested there were no significant differences based on number of years teaching and the six subscales. A post-hoc analysis also identified that there were no significant differences.

\section{Profile Indexes}

The following analyses can better help understand the individuals' scores on the SDS and their personality profiles. Congruence (agreement), Consistency (similarity), and Differentiation (distinctiveness) can all be calculated to compare the data to a norm-referenced sample.

Differentiation. Differentiation refers to the level of distinctiveness of a personality profile and was calculated using the Iachan Differentiation Index. Iachan Differentiation Index Scores $\left(\mathrm{L}_{1}\right)$ ranged from 1.25 to $15(M=7.15, S D=3.09)$. The Iachan Differentiation Index further categorized these scores as high, average, or low. Average scores range from the $86^{\text {th }}$ to the $16^{\text {th }}$ percentile, and high and low scores are above and below this range. Based on the data, percentile ranks ranged from 99th percentile to the 3rd percentile $(M=61.64, S D=26.13)$. The mean percentile for females was $61.85(S D=26.98)$ and for males $60.86(S D=23.27)$; indicating most scores fell within the average range, with some categorized low $(n=2)$ and high $(n=22)$.

Consistency. Consistency is the similarity between the types represented by a single Holland Code and is determined by the position of those types on the RIASEC hexagon. When the first two letters of the code are adjacent, the consistency is high (3); if they are alternate, the consistency is average (2); and, if they are opposite, the consistency is low (1). The mean consistency of all codes was 2.38, indicating an average consistency. $5.8 \%$ of participants had low consistency, $51 \%$ had average consistency, and $43.3 \%$ had high consistency.

\section{Discussion}

This study aimed to identify the personality profiles of practicing SETs and examine the relationship between these profiles and SET Holland Codes. Given the critical shortage of SETs in U.S. public schools, this study is the first to employ the Holland Code as its theoretical model for evaluating SET personality-career profiles and its relevance to teacher retention and attrition. Findings from the overall sample are consistent with Holland's Codes for SETs for possessing social, enterprising, and conventional personality types (Holland, 1997). The social personality type rated highest, suggesting that SETs in our sample typically value assisting others, offering information, solving social problems, and enjoying teaching and helping others accomplish tasks and master goals. The second highest overall scoring profile is enterprising, demonstrating that most SETs favor leadership positions and value 
success in ambition. Finally, the third highest SET personality type is conventional; suggesting that SETs generally appreciate structure and order, especially when working with numbers and written records.

\section{Role of Gender}

Our results demonstrated that SET personality profiles vary according to gender. Specifically, female SETs in our sample were found to have social, conventional, and enterprising personality profiles, whereas male SETs were found to have social, enterprising, and investigative profiles. These differences suggest that female SETs are more likely than males to make set plans and work with order and structure, given their identification with the conventional personality type. However, both female and male SETs identify with the enterprising personality type, suggesting that each gender values ambition and leadership above conducting scientific and analytic thoughts and processes. Given this finding, schools could consider increasing opportunities for SETs to express and demonstrate leadership skills to improve individual-to-profession compatibility, which can influence SETs' decisions on whether or not to remain in the profession. Further, differences in the codes between females and males may indicate why more females enter the teaching profession over males in the U.S.

\section{Role of Setting}

SETs with specific personality types (i.e., artistic, enterprising, and conventional) varied by location. This insinuates that SETs in our sample are more inclined to enter school systems in certain locations based on their personality types. For example, the area's cultural, moral, social, and/or political values may influence a teacher's likeliness to stay in that school over one in a different location. Results indicated that SETs from urban schools were more likely to have artistic personality profiles than SETs in rural schools, suggesting that individuals with more artistic personalities who identify as creative were more likely to work in urban schools than in rural environments. Thus, teachers who may be unsatisfied in rural locations and have a more artistic personality could consider applying for special education positions in more urban settings to increase compatibility between the individual, profession, and location.

\section{Role of Race/Ethnicity}

Although SETs with diverse racial/ethnic backgrounds identified with the Social personality type above others, we found differences among races/ethnicities for the second and third highest-rated personality types. Specifically, our study found that SETs who identify as Hispanic/Latino or Black/African American (two minority populations) are more likely to desire leadership roles and view themselves as ambitious, sociable, and energetic. Interestingly, Black participants were the one group that possessed all three codes that matched with SETs. However, given the limited racial, ethnic, and cultural diversification within our current teaching workforce in the U.S. (Ingersoll et al., 2017a), these findings introduce new questions and concerns surrounding schools' inabilities to accommodate for diverse educators' personality traits, which, in return, may influence attrition. 


\section{Role of Years'Experience}

Lastly, our results suggest that SETs do not vary in personality profiles based on years' experience. The fact that most educators in our study are in their first through fifth year of teaching may play a role in this outcome and should be further investigated in future studies.

\section{Intersection of Factors}

This study identified the influences of three factors (i.e., gender, setting, and race/ethnicity) on the relationship between SET Holland Code profiles and SET occupational codes. Overall, our findings indicated that SETs in the study are most likely to identify with social personality types, regardless of gender and race/ethnicity. This means that female and male SETs who identify as White, Black/African American, Asian/Pacific Islander, Hispanic/Latino, and Native American demonstrate social personality characteristics. These include possessing the tendency to view themselves as helpful, trustworthy, and friendly, enjoying doing things for others and teaching as a profession, and valuing solving social problems. In addition, based upon our finding that both male and female SETs who identify as Hispanic/Latino or black/African American predominantly have the enterprising personality type, this signals the need for schools to consider placing greater emphasis on leadership roles and individual ambition to uphold respect for individual personality attributes and to influence teacher diversification and retention positively.

\section{Limitations}

While the findings suggest that the personality profile for the sample of SETs closely matched the previously determined code assigned to their occupation, we must note some limitations to this study. These limitations should be considered when interpreting the data and findings. First, typical in profile studies, data are based on self-report data, which is susceptible to bias, and the credibility of responses may be a limitation. Yet, we selected the measure and designed questions in a valid and reliable way to measure individuals' personality profiles. Further clarification and in-person guidance may have provided for more accurate results and higher completion rates by participants. The survey participants were asked to complete was also lengthy, which may have impacted this study's attrition and response rates. Next, the survey response rate was just a little more than half (58\%), resulting in a smaller number of participants than we intended to complete the survey. While web-based surveys are known to have on average $15 \%$ less number of participants than mail or in-person surveys and we made multiple follow-up attempts based on recommendations from Dillman (2014), the response rate of $58 \%$ for this study was significantly higher than reported in other web-based surveys (Lefever et al., 2007; Manfred et al., 2008). Further, participants were from one teacher preparation program made up of mostly White females, which could be identified as a limitation. A more representative sample of SETs across the U.S. would make claims more valid in the current study. Thus, generalizing our findings to the entire population of special educators should be considered with caution. However, with SETs being the top critical shortage in education (and the region in which this study was conducted), these findings provide information that can be used later in national studies. 


\section{Future Directions}

Given that school and teacher characteristics impact teacher attrition and retention rates (CarverThomas \& Darling-Hammond, 2017), future research should expand the investigation to include a more diverse sample of SETs working in a variety of school locations, including urban and rural sites. Identifying a relationship between personality profiles of SETs and specific environmental characteristics lays the groundwork for teacher preparation programs to properly train teachers to understand the demands of teaching special education and what is needed to be successful. An example of this could include offering field experiences early on for teachers to understand and personally identify if the career choice is right for them. Next, the SDS could be used as a tool for teacher induction into teacher preparation programs or schools to better understand the profiles of the students/teachers so administrators can better understand how to successfully support teachers.

However, there is still further examination needed of the personality profiles of SETs. For example, since female teachers in our sample have social, conventional, and enterprising personality profiles, this may indicate why more females enter the U.S. teacher professions over males. Thus, further investigations should consider gender and personality profiles, and considerations for recruiting and retaining SETs. Nevertheless, the current research provides an increased understanding of personality profiles and may provide insight about those who enter or leave the profession. Further, varying personality profiles indicate a need to diversify the way teacher preparation is offered; some may do better in alternate route programs than traditional teacher preparation programs and may need different types of supports and structures to succeed.

\section{Conclusion}

This study sought to understand the personality profiles of SETs entering the workforce and identify if their profiles matched SETs personality codes. While there have been no studies, to our knowledge, that have previously investigated this area, it was identified that a majority of the teachers in the teacher preparation program possessed the occupational code that matched the SET personality code. Yet, it was identified that occupational personality profile codes may differ between genders, location, and race/ethnicity. While self-report data is a known limitation, understanding individuals' personality profiles and how it matches with occupation codes is important when determining teacher preparation programming and support needed in the schools.

The SET teacher shortages continue to be "severe and persistent" (Carver-Thomas \& DarlingHammond, 2017, p. 13). Significant shortages are reported across 48 of the 50 states, and turnover rates increase, understanding the number that may contribute to these alarming numbers is critical. While some of the factors for increased attrition rates include difficult working conditions and low job satisfaction, research indicates individuals are more likely to continue employment in an organization or job that is matched to their personalities (Swanson, 2012). Thus, the association of personality profiles and job retention, related to SETs, needs to continue to be investigated. Examining the relationship between the personality profiles of SETs and the related occupational codes based on Holland's theory began to fill a gap in research and can offer school leaders information that can be used to reverse the persistent trend in shortages of SETs. 


\section{Declaration of Conflicting Interests}

The author declared no potential conflicts of interest with respect to the research, authorship, and/or publication of this article.

\section{Funding}

The authors received no financial support for this research.

\section{ORCID iD}

LaRon A. Scott (iD https://ocrid.org/0000-0002-2264-6334

Lauren Bruno (D) https://orcid.org/0000-0001-47316-1268

Philip Gnilka (iD https://orcid.org/0000-0002-4505-4171

Katherine Brendli (iD https://orcid.org/0000-0003-4066-9027

\section{References}

Berkovich, I. (2018). Conceptualizations of empathy in K-12 teaching: A review of empirical research. Educational Review, 72(5), 547-566. https://doi.org/10.1080/00131911.2018.1530196

Beteille, T., Kalogrides, D., \& Loeb, S. (2009). Effective schools: Managing the recruitment, development, and retention of high-quality teachers. National Center for Analysis of Longitudinal Data in Education Research (CALDER), Working Paper, 37. https://caldercenter.org/sites/default/files/Effective-Schools_CALDER-Working-Paper-373.pdf

Bettini, E., Jones, N., Brownell, M., Conroy, M., Park, Y., Leite, W., Crockett, J., \& Benedict, A. (2017). Workload manageability among novice special and general educators: Relationships with emotional exhaustion and career intentions. Remedial and Special Education, 38(4), 246-256. https://doi.org/10.1177/0741932517708327

Billingsley, B., \& Bettini, E. (2019). Special education teacher attrition and retention: A review of the literature. Review of Educational Research, 89(5), 697-744. https://doi.org/10.3102/0034654319862495

Buttner, S., Pijl, S. J., Bijstra, J., \& van den Bosch, E. (2015). Personality traits of expert teachers of students with behavioural problems: A review and classification of the literature. The Australian Educational Researcher, 42(4), 461-481. https://doi.org/10.1007/s13384-015-0176-1

Carver-Thomas, D., \& Darling-Hammond, L. (2017). Teacher turnover: Why it matters and what we can do about it. Learning Policy Institute. https://learningpolicyinstitute.org/sites/default/files/productfiles/Teacher Turnover REPORT.pdf

Conley, S., \& You, S. (2017). Key influences on special education teachers' intention to leave: The effects of administrative support and teacher team efficacy in a mediation model. Education Management Administration \& Leadership, 45(3), 521-540. https://doi.org/10.1177/1741143215608859

Connelly, V., \& Graham, S. (2009). Student teaching and teacher attrition in special education. Teacher Education and Special Education, 32(3), 257-269. https://doi.org/10.1177/0888406409339472 
Fouad, N. (2002). Cross-cultural differences in vocational interests: between-groups differences on the Strong Interest Inventory. Journal of Counseling Psychology, 49(3), 283-289. https://doi.org/10.1037/0022-0167.49.3.282

Goldberg, L. (1990). An alternative" description of personality": The big-five factor structure. Journal of personality and social psychology, 59(6), 1216-1229. https://doi.org/10.1037/0022$\underline{3514.59 .6 .1216}$

Goldring, R., Taie, S., \& Riddles, M. (2014). Teacher attrition and mobility: Results from the 2012-13 Teacher Follow-up Survey (NCES 2014-077). U.S. Department of Education, National Center for Education Statistics. https://nces.ed.gov/pubs2014/2014077.pdf

Gottfredson, G., \& Holland, J. (1990). A longitudinal test of the influence of congruence: Job satisfaction, competency utilization, and counterproductive behavior. Journal of Counseling Psychology, 37(4), 389-398.https://doi.org/10.1037/0022-0167.37.4.389

Grissom, J., Viano, S., \& Selin, J. (2015). Understanding employee turnover in the public sector: Insights from research on teacher mobility. Public Administration Review, 76(2), 241-251. https://doi.org/10.1111/puar.12435

Hagaman, J., \& Casey, K. (2017). Teacher attrition in special education: Perspectives from the field. Teacher Education and Special Education, 41(4) 277-291. https://doi.org/10.1177/0888406417725797

Holland, J. (1966). A psychological classification scheme for vocations and major fields. Journal of Counseling Psychology, 13(3), 278-288. https://doi.org/10.1037/h0023725

Holland, J. (1985). Making vocational choices. Prentice-Hall.

Holland, J. (1997). Making vocational choices: A theory of vocational personalities and work environments (3rd ed.). Psychological Assessment Resources.

Holland, J., Messer, M. (2013). Self-Directed Search (SDS) professional manual(5th ed.). Psychological Assessment Resources.

Holland, J., Sorensen, A., Clark, J., Nafziger, D., \& Blum, Z. (1973). Applying an occupational classification to a representative sample of work histories. Journal of Applied Psychology, 58(1), 34-41. https://doi.org/10.1037/h0035405

Hurtado Rúa, S., Stead, G., \& Poklar, A. (2018). Five-factor personality traits and RIASEC interest types: A multivariate meta-analysis. Journal of Career Assessment, 27(3), 527-543. https://doi.org/10.1177/1069072718780447

Individuals With Disabilities Education Act, 20 U.S.C. $§ 1400$ et seq. (2004).

Ingersoll, R., May, H., \& Collins, G. (2017a). Minority teacher recruitment, employment, and retention: 1987 to 2013. Learning Policy Institute. https://learningpolicyinstitute.org/sites/default/files/productfiles/Minority Teacher Recruitment REPORT.pdf

Ingersoll, R., Merrill, L., \& May, H. (2014). What are the effects of teacher education and preparation on beginning teacher attrition? Consortium for Policy Research in Education Research Reports. https://repository.upenn.edu/cpre researchreports/78

Ingersoll, R. Merrill, L., Owens, C., \& Zuckerberg, A. (2017b). A quarter century of changes in the elementary and secondary teaching force: From 1987 to 2012. Statistical Analysis Report (NCES 2017-092). U.S. Department of Education, National Center for Education Statistics. https://nces.ed.gov/pubs2017/2017092.pdf 
Ingersoll, R., \& Strong, M. (2011). The impact of induction and mentoring programs for beginning teachers: A critical review of the research. Review of Educational Research, 81(2), 201-233. https://doi.org/10.3102/0034654311403323

Irwin, V., Zhang, J., Wang, X., Hein, S., Wang, K., Roberts, A., York, C., Barmer, A., Bullock Mann, F., Dilig, R., and Parker, S. (2021). Report on the Condition of Education 2021 (NCES 2021144). U.S. Department of Education, National Center for Education Statistics. https://nces.ed.gov/pubsearch/pubsinfo.asp?pubid=2021144

Jennings, B. (2008). Work stress and burnout among nurses: Role of the work environment and working conditions. In R. Hughes (Ed.), Patient safety and quality: An evidence-based handbook for nurses (pp. 2-137-2-158). Agency for Healthcare Research and Quality. https://www.ncbi.nlm.nih.gov/books/NBK2668/

Kim, L., Jörg, V., \& Klassen, R. (2019). A meta-analysis of the effects of teacher personality on teacher effectiveness and burnout. Education Psychology Review, 31(1), 163-195. https://doi.org/10.1007/s10648-018-9458-2

Kristof, A. (1996). Person-organization fit: An integrative review of its conceptualizations, measurement, and implications. Personnel Psychology, 49(1), 1-49. https://doi.org/10.1111/j.1744-6570.1996.tb01790.x

Larson, L., Rottinghaus, P., \& Borgen, F. (2002). Meta-analyses of big six interests and big five personality factors. Journal of Vocational Behavior, 61(2), 217-239. https://doi.org/10.1006/jvbe.2001.1854

Maslach, C., Schaufeli, W., \& Leiter, M. (2001). Job burnout. Annual Review of Psychology, 52(1), 397-422. https://doi.org/10.1146/annurev.psych.52.1.397

Mehrenberg, R. (2013). Red tape and green teachers: The impact of paperwork on novice special education teachers. International Journal of Special Education, 28(1), 80-87.

Merrit, E., Wanless, S., Rimm-Kaufman, S., Cameron, C., \& Peugh, J. (2012). The contributions of teachers' emotional support to children's social behaviors and self-regulatory skills in first grade. School Psychology Review, 41(2), 141-159. https://doi.org/10.1080/02796015.2012.12087517

Morris, M. (2016). Vocational interests in the United States: Sex, age, ethnicity, and year effects. Journal of Counseling Psychology, 63(5), 604-615. https://doi.org/10.1037/cou0000164

Nauta, M. (2010). The development, evolution, and status of Holland's theory of vocational personalities: Reflections and future directions for counseling psychology. Journal of Counseling Psychology, 57(1), 11-22. https://doi.org/10.1037/a0018213

Perera, H., Granziera, H., \& Mcllveen, P. (2018). Profiles of teacher personality and relations with teacher self-efficacy, work engagement, and job satisfaction. Personality and Individual Differences, 120,171-178. https://doi.org/10.1016/i.paid.2017.08.034

Platsidou, M., \& Agaliotis, I. (2017). Does empathy predict instructional assignment-related stress? A study in special and general education teachers. International Journal of Disability, Development and Education, 64(1), 57-75. https://doi.org/10.1080/1034912X.2016.1174191

Prather-Jones, B. (2011). "Some people aren't cut out for it": The role of personality factors in the careers of teachers of students with EBD. Remedial and Special Education, 32(3), 179-191. https://doi.org/10.1177/0741932510362195 
Robinson, O., Bridges, S., Rollins, L., \& Schumacker, R. (2019). A study of the relation between special education burnout and job satisfaction. Journal of Research in Special Educational Needs, 19(4), 295-303. https://doi.org/10.1111/1471-3802.12448

Scott, L., Taylor, J., Bruno, L., Padhye, I., Brendli, K., Wallace, W., Cormier, C.J. (2021). Why do they stay? Factors associated with special education teachers' persistence. Remedial and Special Education. https://doi.org/10.1177/07419325211014965

Skaalvik, E., \& Skaalvik, S. (2010). Teacher self-efficacy and teacher burnout: A study of relations. Teaching and Teacher Education, 26(4), 1059-1069. https://doi.org/10.1016/j.tate.2009.11.001

Smith, T., \& Ingersoll, R. (2004). What are the effects of induction and mentoring on beginning teacher turnover? American Educational Research Journal, 41(3), 681-714. https://doi.org/10.3102/00028312041003681

Sutcher, L., Darling-Hammond, L., \& Carver-Thomas, D. (2016). A coming crisis in teaching? Teacher supply, demand, and shortages in the US. Learning Policy Institute. https://learningpolicyinstitute.org/sites/default/files/productfiles/A_Coming_Crisis in_Teaching_REPORT.pdf

Swanson, P. (2008). The RIASEC profile of foreign language teachers. The Journal of Vocational Behavior, 72(1), 25-30. https://doi.org/10.1016/i.jvb.2007.10.012

Swanson, P. (2012). The congruence of vocational interests and the workplace environment: Reducing the language teacher shortage. Language Teaching Research, 16(4), 519-537. https://doi.org/ $10.1177 / 1362168812455588$

Tak, J. (2011). Relationships between various person-environment fit types and employee withdrawal behavior: A longitudinal study. Journal of Vocational Behavior, 78(2), 315-320. https://doi.org/10.1016/i.jvb.2010.11.006

Tracey, T., \& Robbins, S. (2005). Stability of interests across ethnicity and gender: A longitudinal examination of grades 8 through 12. Journal of Vocational Behavior, 67(3), 335-364. https://doi.org/10.1016/i.jvb.2004.11.003

U.S. Department of Education. Institute of Education Sciences, National Center for Education Statistics. (2018). Digest of Education Statistics. https://nces.ed.gov/programs/digest/2018menu tables.asp

U.S. Department of Education, Institute of Education Sciences, National Center for Education Statistics. (2021). Students with disabilities. The condition of education. https://nces.ed.gov/programs/coe/indicator/cgg

Wampold, B., Ankarlo, G., Mondin, G., Trinidad-Carrillo, M., Baumler, B., \& Prater, K. (1995). Social skills of and social environments produced by different Holland types: A social perspective on person-environment fit models. Journal of Counseling Psychology, 42(3), 365-379. https://doi.org/10.1037/0022-0167.42.3.365

Zysberg, L., Orenshtein, C., Gimmon, E., \& Robinson, R. (2017). Emotional intelligence, personality, stress, and burnout among educators. International Journal of Stress Management, 24(Suppl 1), 122-136. https://doi.org/0.1037/str0000028 